\title{
How Adolescents Come to See Themselves as More Responsible Through Participation in Youth Programs
}

\author{
Dustin Wood \\ Wake Forest University
}

\author{
Reed W. Larson and Jane R. Brown \\ University of Illinois at Urbana-Champaign
}

\begin{abstract}
This qualitative study was aimed at developing theory about the process underlying the development of responsibility grounded in accounts of youth who reported experiencing this change. A total of 108 high-schoolaged $(M=16.5)$ youth from 11 programs were interviewed about their experiences within the program, and 24 reported becoming more responsible through their participation. The youth's accounts suggested that this process was driven largely by successfully fulfilling program expectations. This process was driven by youth's adherence to their commitments and their consideration of the consequences of their actions on others. Youth mentioned changes in responsibility most frequently in three programs, which appeared to differ from the remaining programs in having more structure and placing greater ownership and accountability on youth.
\end{abstract}

Many youth programs have the objective of promoting the development of responsibility in their members. The mission statement of the Girl Scouts of the USA (2007), for example, includes the goal of having girls learn "the importance of personal responsibility, the value of goal-setting, the spirit of teamwork, and the thrill of accomplishment." The mission statements of the National FFA Organization (2007) and the Boy Scouts of America (2007) identify similar developmental goals as major, overarching goals of their programs. In a study of 48 effective youth programs, $81 \%$ included the development of characteristics such as responsibility in their list of major goals (Roth \& Brooks-Gunn, 2003). An important task for research is to understand the process that underlies the development of responsibility, as well as the features of environments that support this process.

Responsibility is typically defined as the quality of being someone who can be counted on to fulfill obligations (Winter, 1992), and self-report measures of responsibility and related dispositions have been found to be associated with success at work (Barrick \& Mount, 1991; Judge, Heller, \& Mount, 2002), academic performance (Noftle \& Robins, 2007), mental health (Saulsman \& Page, 2004; Yalom, 1980), quality of close

This research was supported by a grant from the William T. Grant Foundation. We thank the adult leaders and youth of the programs we studied for sharing their experiences with us. All names of programs, youth, and adult leaders in this article are pseudonyms. Small inconsequential changes were made in the descriptions of some youth's activities to preserve their anonymity. We also thank Donald Tyler for contributions to the analyses for the article.

Correspondence concerning this article should be addressed to Dustin Wood, Department of Psychology, Wake Forest University, 438 Greene Hall, Winston-Salem, NC 27109. Electronic mail may be sent todwood@wfu.edu. relationships (Roberts \& Bogg, 2004), and health behaviors associated with longevity (Bogg \& Roberts, 2004). Seeing oneself as responsible also appears to become increasingly important with age. Young people report that responsibility is a central characteristic needed to consider oneself an "adult" (Arnett, 2000), and there is evidence that irresponsibility becomes increasingly associated with social exclusion and other negative social evaluations as individuals progress from adolescence to adulthood (Wood, Gosling, \& Potter, 2007; Wood \& Roberts, 2006). Given these findings, it is not surprising that national panels include the development of responsibility as an essential goal in preparing youth for adulthood (Partnership for 21st Century Skills, 2003; Secretary's Commission on Achieving Necessary Skills [SCANS], 1991).

Our objective in the current research is to understand how experiences in youth programs may facilitate the development of responsibility. Studies have shown that participation in youth programs is associated with positive long-term school, career, and health outcomes (Eccles, Barber, Stone, \& Hunt, 2003; National Research Council Institute of Medicine [NRC], 2002). Research is needed, however, to understand the developmental processes that lead to these outcomes (Mahoney, Larson, Eccles, \& Lord, 2005). Our focus on the process of responsibility development emerged from preliminary analyses of data from a larger study concerned with positive development in youth programs (Larson et al., 2004). These analyses indicated that gaining responsibility was

\footnotetext{
(C) 2009, Copyright the Author(s)

Journal Compilation (C) 2009, Society for Research in Child Development, Inc. All rights reserved. 0009-3920/2009/8001-0022
} 
a salient theme in a number of youth's ongoing accounts of how they had changed through their participation. To investigate this change, we employed an ecological framework that conceptualizes development as occurring through proximal processes experienced by individuals, which are influenced by dynamic features of their larger environments (Bronfenbrenner, 1999; Spencer, 2006). We used qualitative methods of discovery research because our aim was to formulate preliminary empirically based theory on these processes and dynamic features in context (National Institutes of Mental Health Consortium of Editors on Development and Psychopathology, 1999).

\section{Understanding the Development of Responsibility}

Recent research in other contexts indicates that experiences within social roles and relationships can influence the development of responsibility. Responsibility and related facets of conscientiousness have been found to increase among individuals involved in marital relationships (Roberts \& Bogg, 2004) and due to work experiences, such as being promoted to a higher status job (Roberts, 1997; Roberts, Caspi, \& Moffitt, 2003). Research with children suggests that a parent's responsiveness and disciplinary style may be associated with the development of a child's level of conscience and effortful control (Kochanska, 1997; Kochanska, Murray, \& Harlan, 2000). In adolescence, it has been suggested that higher levels of personal responsibility could result from the demands youth face in completing homework (Warton, 2001).

The common elements linking these social experiences to the development of responsibility may be encountering and then successfully enacting new behavioral demands and expectations (Roberts, Wood, \& Smith, 2005; Wood et al., 2007). This would be consistent with Aristotle's (trans. 1962) suggestion that "we become just by the practice of just actions, self-controlled by exercising self-control, and courageous by performing acts of courage." Restated for the issue at hand, we may become responsible by successfully and repeatedly carrying out our responsibilities. The modern elaboration of this idea suggests that the continued enactment of particular behavioral patterns (e.g., acting responsibly in response to demands) leads to the development of more general propensities to perform them in similar situations in the future (Wilson, 2002; Wood, 2007). In the current study, we examine whether and how demands and expectations are part of the change process in youth's accounts of becoming more responsible.
If carrying out demands is part of the mechanism underlying the development of responsibility, it raises another important concern. What motivates youth to comply when they encounter new and more challenging demands? Sampson and Laub (1992) proposed that this adherence may come principally from external social controls: Individuals may come to act more responsibly to avoid the negative consequences (particularly disapproval and rejection) that accompany failure to measure up to other's expectations. Roberts and colleagues (Roberts \& Wood, 2006; Roberts et al., 2005) have suggested that social investments are also an important aspect of the process, where individuals come to act more responsibly because they willingly commit themselves to social roles and their associated expectations. We thus examine the reasons or motives that youth provide in describing why they stick with difficult or aversive program demands.

\section{The Current Investigation}

The overarching goal of the current study was to understand how youth come to see themselves as more responsible through participation in youth programs. Based on ideas discussed above, we examined youth's accounts of becoming more responsible with a focus on three questions. First, what role did demands and expectations play in this process, and what forms did these demands take? Second, if demands were central to the development of responsibility, why did youth accept and execute the demands they encountered? These first two questions address the process underlying the development of responsibility. The third question is, what features of program environments might have facilitated this process? Bronfenbrenner (1999) suggests that an environment can influence development either "by setting proximal processes in motion and sustaining their operation at a high level or by reducing opportunities for their initiation and exposing them to sources of environmental interference" (p. 12). We decided to investigate how program environments might set the process of developing responsibility in motion (or interfere with it) after discovering that the programs we studied differed significantly in the number of youth who reported becoming more responsible through participation. Comparison of programs with high and low rates of youth reporting this change thus afforded the opportunity to examine how the process of responsibility development might be promoted by the program's leaders or culture.

Our general strategy was to identify clear cases where youth experienced becoming more responsible 
and focus our analyses on understanding the accounts of this process given by these youth (Creswell, 1998; Moustakas, 1994). Although our research questions emerged from the literature, our objective was to address these questions with a discovery-oriented research strategy. To derive theory about youth's process of responsibility development (Questions 1 and 2), we focused on youth reports because we sought to understand their experience of the change process (Auerbach \& Silverstein, 2003; Lincoln \& Guba, 1985). Research shows that adolescents are able to provide coherent accounts of how their experiences are related to self-change (Habermas \& Bluck, 2000) and that self-reported assessments of personality development are correlated to actual personality change over time as measured by personality inventories (Robins, Noftle, Trzesniewski, \& Roberts, 2005). To evaluate differences between programs (Question $3)$, we utilized information from interviews with adult leaders of the programs, as well as from site observations. This information allowed us to investigate how features of the program external to youth (e.g., leaders' philosophies and ways of acting) might facilitate or interfere with youth's engagement in the process of responsibility development.

\section{Method}

\section{Programs and Youth Studied}

The research was conducted with high-schoolaged youth in 11 urban and rural youth development programs (Larson, Pearce, Sullivan, \& Jarrett, 2007). Because the objective was to observe the development taking place, the study focused on programs that had reputations as high quality. These programs were identified following procedures for selecting highquality programs developed by McLaughlin, Irby, and Langman (1994). We first asked local youth development professionals about good programs in their areas. When a program was named by more than one person, we visited it and talked with program staff and youth to verify that the program was effective in engaging participants and had other features associated with high-quality programs (McLaughlin, 2000; NRC, 2002). The 11 programs included arts, media arts, leadership, and service programs (Table 1). In three of the programs (Art-First, Media Masters, and Harambee), youth were paid an approximately minimum wage for participation.

Youth in all 11 programs were involved in joint or individual projects. The programs were studied over a natural period of the youth's work, typically 3-4 months (range 2-9 months). The sample for the research included 8-12 youth in each program, for a total of 108 youth interviewed across programs. These youth were selected, with input from the leaders, to be representative of program participants in ethnicity, gender, and length of prior participation in the program. The sample included 59 girls and 49 boys, with a mean age of $16.5(S D=1.7$, range $=13-$ $21)$, and approximately equal numbers of European American $(N=36)$, African American $(N=32)$, and Latino $(N=32)$ youth, as well as 6 biracial and 2 Asian youth.

\section{Procedures}

Youth in the study were interviewed approximately every 2 weeks over the course of the research period at each program. In-depth face-to-face interviews (lasting 45-70 min) were conducted at the beginning, middle, and end of this period. Shorter biweekly interviews (lasting 10-20 min) were conducted by phone in the intervening intervals. All interviews were tape-recorded and transcribed. A total of 648 interviews were conducted with the youth from the 11 programs. Interviews were also conducted with one to two adult leaders at each program following the same schedule used with the youth (a total of 122 interviews). In addition, site observations were conducted approximately every 1 to 2 weeks (a total of 159).

\section{Interview and Research Protocols}

The flexible interview protocols were designed to elicit youth's narrative descriptions of their ongoing experiences in the programs and how they were affected by these experiences. The protocol included a range of open-ended questions on different areas of development, such as identity, initiative, and social relationships. Youth were encouraged to describe salient experiences and changes in themselves (Auerbach \& Silverstein, 2003).

Youth's reports of the development of responsibility emerged from these narrative responses. Most of the participants who identified themselves as becoming more responsible through program participation did so in response to the open-ended question: "How has participation in [this program] changed parts of you in any way?" which was asked in the longer initial, midpoint, and final interviews. Some youth reported becoming more responsible in the shorter phone interviews, either in response to a question asking about their change and growth in the program, 


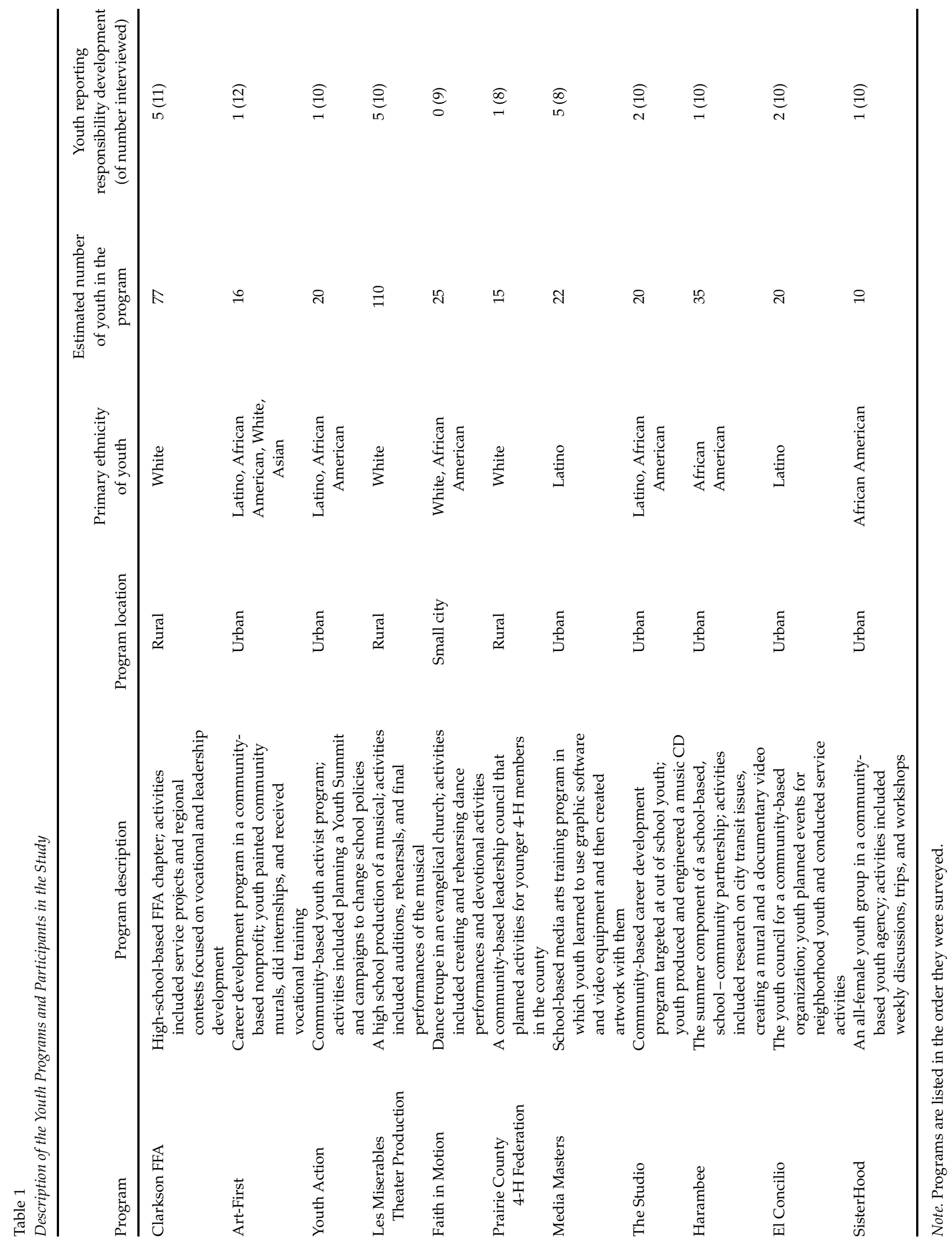


or more spontaneously during other questions concerning their recent experiences in the program. When individuals mentioned any change that occurred through program participation (such as becoming more responsible), interviewers were instructed to follow up this statement by asking how this change came about. Thus, we obtained their narrative accounts of the process of change. We have sometimes drawn on material from prior interviews to put these accounts into a larger temporal context.

It is important to note that there were no questions in the interviews that directly asked youth whether they had developed responsibility. Consistent with methods of discovery research (Auerbach \& Silverstein, 2003), our aim was to allow youth to identify the most salient changes they experienced through program involvement, without imposing the researchers' language or theoretical framework onto these accounts. This approach likely resulted in fewer accounts of youth acquiring responsibility than would have been obtained with direct questioning. However, we felt that requiring youth to spontaneously mention increases in responsibility without being directly prompted provided greater confidence that the cases of responsibility development we identified were clear-cut and reflected the youth's lived experience, as opposed to representing acquiescence or compliance with the researchers' agenda.

The interviews with the adult leaders also followed an open-ended protocol. They dealt with the leaders' philosophy, events within the program, challenges leaders faced in working with the youth and their responses to these challenges, and how they aimed to facilitate youth's growth and development. Site observations were conducted using standard procedures of participant observation whereby the researcher observed sessions in a friendly but minimally obtrusive way and recorded field notes on events and verbal behavior (Jorgensen, 1989).

\section{Data Coding and Analysis}

We used methods of qualitative and grounded theory data analysis to identify patterns in the youth's reports on their experiences (Auerbach \& Silverstein, 2003; Strauss \& Corbin, 1998; Taylor \& Bogdan, 1998). Our first step involved developing criteria to define which youth reported becoming more responsible through program experiences. Youth were identified as experiencing increased responsibility if they mentioned: (a) becoming "more responsible," (b) becoming "more mature" in a way that indicated they now tended to fulfill obligations handed to them more often, or (c) becoming "more self-disciplined" or having "more will-power," as indicated by becoming better able to fulfill tasks. These three criteria were chosen because self-perceptions of responsibility are found to be closely related to self-perceptions of maturity (Arnett, 2000; Hogan \& Roberts, 2004) and self-control (Roberts, Bogg, Walton, Chernyshenko, \& Stark, 2004). This coding was done by the first and third authors. We assess interrater reliability by having the two coders independently evaluate whether responses to the standard "how have you changed" question met the above criteria. These independent evaluations showed substantial agreement $(\kappa=.83)$. To protect against false positives, a passage was counted as reflecting responsibility development only when both raters agreed that it met the criteria.

Analyses for the first two research questions entailed coding and evaluating the youth's descriptions of demands that resulted in their change in responsibility and of why they accepted and adhered to these demands. Following procedures of grounded theory analyses (Strauss \& Corbin, 1998), we first identified the themes reflected in a youth's answers to these questions, then grouped similar responses into a smaller number of categories, and interpreted the underlying patterns.

Analyses addressing our third research question were aimed at identifying the dynamic features of programs associated with responsibility development. To do this, we compared programs with high and low percentages of youth reporting that participation resulted in increased responsibility. We employed matrix-based qualitative analysis (Miles \& Huberman, 1994), where we first developed a set of working hypotheses regarding the features that distinguish these programs. We then read through the leader interviews for each program and identified all statements that were indicative or counterindicative of these features. Finally, we carried out iterative steps comparing the programs that were high and low in responsibility development for each feature. This process resulted in ruling out several hypothesized features that did not differentiate the high and low programs (e.g., leader monitoring) and revising the operational definitions for several features to differentiate better the high and low programs.

\section{Results}

Identification of Youth Who Experienced Increased Responsibility

Of the 108 youth interviewed across the 11 programs, 24 reported becoming more responsible 
through their involvement in the programs. These 24 youth did not differ noticeably from others by gender, age, or length of participation in the program. Most of the youth used the word "responsible" explicitly to describe their change. For instance, Jennie, a member of the Clarkson FFA, credited the program with making her "a lot more responsible and motivated." Pasco at Media Masters recalled that "I'm more responsible now with my work." Heather from the Les Miserables production reported that she learned "a lot more responsibility, individual responsibility, being extra careful to take care of myself, hav[ing] self-discipline to know when I can and can't go out with friends after rehearsals, things like that." As described in the Method section, some youth described the change using language with similar meaning. Peter, a student in Les Miserables, recalled that he was "becoming more serious with the things I $\mathrm{do}^{\prime \prime}$ as a result of participating in the program, and Charnise from SisterHood reported that "I've become a little bit more hard-working, especially getting things done on time."

The majority of youth reporting increased responsibility came from three programs (Table 1). At Media Masters, the Les Miserables theater production, and the Clarkson FFA, 5 youth in each (more than $45 \%$ of the interviewees) reported gaining responsibility, while 2 or fewer youth (less than 25\%) reported this at each of the remaining eight programs. The likelihood of reporting this change differed significantly across the 11 programs $\left(\chi^{2}=22.41, d f=10, p=.025\right)$, suggesting that these three programs may have provided more favorable environments for the development of responsibility than the remaining eight programs. We first examine the "proximal processes" experienced by the 24 youth and then examine the distinct features of these three programs that may have facilitated these processes.

\section{Types of Demands That Led to Changes in Perceived Responsibility}

The analysis for Question 1 showed that these 24 youth regularly attributed their increased sense of responsibility to fulfilling demands and expectations. These included expectations they had met, obligations they had fulfilled, and challenging circumstances where they had acted in a dependable way. To identify the forms these demands took, grounded theory analyses were conducted on all statements by youth in which they described the process of developing responsibility. This led to the identification of three interrelated types of demands associated with youth coming to see themselves as more responsible: task demands, demands of program roles, and time demands.

Task demands. Task demands included challenges related to the achievement of group or individual projects within the program. Youth at Media Masters mostly worked on individual projects, and Pasco, along with other students in that program, attributed his development of responsibility to "how we had to finish our work, and always finish it. Never leave it undone or leave it half done." Youth in the Clarkson FFA had more collaborative activities, and Sarah reported learning to act more responsibly when she was preparing for a team competition: "You have to carry your own. Mr. Baker and Mr. Jensen [the FFA advisors], they'll push you, they'll give you an encouragement, but they're not going to do it for you: no way, shape, or form." Similarly, Lori, recalled that she started seeing herself as responsible when the FFA leaders entrusted her to perform duties such as calling people for a blood drive. Later she explained discovering that, "You work as a team individually. You do a lot of stuff individually that you're doing, not for yourself, but for everyone else." Youth came to understand that working on group projects did not imply a diffusion of personal responsibility, but that each youth had to do his or her part.

A more in-depth example of how task demands led to development of responsibility was provided by Sarah's description of her experiences on an individual project. She had decided to raise pigs to enter into the competition for a state FFA award. She reported that "this summer I am kind of getting used to: It's just me. I'm the one that has to push myself to do these things no matter how badly I do not want to go step in that pigpen and what not, I gotta do it, gotta do it." Raising pigs involved unpleasant tasks, but Sarah recognized that the work needed to be done and that, if she did not do it, no one else would. This point was driven home for her when during a streak of particularly hot summer weather, her pigs were in danger of dying, and a redoubling of her effort was needed to keep them alive and healthy. Sarah, like some other youth, described responsibility as following from experiences in which the requirements of the task became much larger than she had initially expected, and fulfillment of these requirements depended on her alone.

Demands of program roles. Some of the demands through which youth learned responsibility were related to roles that youth held within the program. These included formal roles, like president, lighting director, or committee chair, as well as more informal roles, such as being a veteran program member. At the FFA program, youth ran for and were elected to 
positions as officers. In this and other programs, youth also chose roles or were assigned to roles by adult leaders, thus taking on the accompanying expectations as well as any unexpected challenges that emerged.

Several youth who reported becoming more responsible attributed the change to the demands of holding a formal role. Jeff pointed to the duties associated with his role as president of the Clarkson FFA: "Being President, there's lots of stuff you have to do in the chapter, and [you] just gotta make sure everything is done by a set time." Lori, who was also an FFA officer, reported becoming more responsible through learning how to interact with other youth in groups: "If you wanna be a chapter officer, then you've gotta treat others with respect and the way you wanna be treated, and you've gotta prove yourself [to be] responsible and mature and things like that." Similarly, Heather was the stage manager for the production of Les Miserables, and she attributed her increase in responsibility to carrying out the demands entailed in managing fellow students.

Other youth reported that holding informal roles facilitated their development of responsibility. Peter, an upper-level student in Les Miserables, felt that certain behavior was expected from him due to the unofficial role of being an older student in the production: "You have to set an example and stuff cause you're an upperclassman. I think it puts a lot more responsibility on you and I think that's affecting just overall." Indeed, adult leaders of the Les Miserables production communicated an expectation that older members of the cast and crew show leadership and set good examples.

Time demands. A number of youth described time demands as central to their experience of becoming more responsible. This was particularly common in the Les Miserables production, which required 10-20 $\mathrm{hr}$ of involvement per week. These youth frequently expressed the need to reorganize or restrict other activities in their lives in order to fulfill duties of the program. In the early stages of rehearsals, Heather, like other youth in the production, reported that she was stressed for time and tired a lot. But she also said "I have to get through it." It was much later in the production schedule that she reported becoming more responsible. She explained:

I [had] to learn that you have to be organized with your time and use your time wisely. Especially with sleep and things like that, because I think that I have seen a total of three meals in the last three days, just because I'm running from one place to the next and there are not enough hours in the day.
Heather reported learning that she had to "take care of myself and make sure I'm sleeping" as well as the need to turn down friends who wanted to go out after rehearsals, so that she could stay on top of the demands of the program and school.

Other youth reported similar experiences. Victoria in Media Masters said she worked harder to budget her time in response to expectations that she arrive to the program and finish projects in a timely fashion. She realized that "if I come out at 2:00 from school, I have an hour between [the end of school and the start of the program]. I need to figure out what I'm going to do to be there on time." For Manuel from Art-First, a demand on his time that helped him learn responsibility was getting up early in the morning to make the long commute through the city to get to the program every morning. He explained, "I had to get here sometimes at 9 o'clock, so I'd have to get up at 6 or something to get over here and make it on time. And just make sure all my duties are done." This challenge was particularly salient to him given the late-night schedule that he had maintained before entering the program.

In sum, task, role, and time demands appeared to be central to youth accounts of change. These youth reported wanting to live up to the demands they faced, even when this required performing difficult or onerous tasks (e.g., cleaning up after pigs, working long hours, and meeting tight deadlines) or sacrificing time with friends. In the youth's accounts, it was their success in meeting these demands that made them see themselves as more responsible.

\section{Reasons Individuals Accepted and Adhered to the Demands}

The fact that the demands required effort and were not always enjoyable leads to our second question: Why did youth decide to perform these tasks? Indeed, the adult leaders reported cases where youth did not fulfill expected demands. A few youth in the programs quit, and a number of the youth we interviewed expressed thoughts about quitting due to the expectations and demands. Suzanne in the Les Miserables production described her moments of doubt:

[When you're in the musical] you get sleep but it's still not enough, where on the weekends you're sleeping in really late and still really tired and it feels like you have done nothing, even though you have done like a million things. So that was a big thing that really made me want to quit.

To address the second question, we analyzed quotes where these 24 youth discussed why they 
performed demands that they encountered, including their responses to questions asking whether they ever had thoughts of quitting and how they responded to those thoughts. These analyses led to the identification of three themes.

Carrying out one's commitments. The most frequent reason youth gave for adhering to demands was their experience of an obligation to do so. They used phrases like "we had to" or "you gotta" and invoked the commitment they had made to explain why they fulfilled the demands.

Youth in Media Masters, who were paid for their participation in the program, reported adhering to expectations because they thought of it as a job. Victoria described her duties to include "being there the times I'm suppose to be there; I'm responsible like to respect others and follow the rules." Pasco indicated a similar sense of obligation and attributed it to the role requirements that come with holding a job: "Because there, you're almost like an adult. You have a job, so you have to act more mature." The youth had accepted the obligations of the job as their own.

Youth in Les Miserables described being motivated by their commitment to the production. Heather, the stage manager, described regularly encountering a temptation to quit as the time demands made it more and more difficult to complete her homework, but said she never came close to actually doing it: "I have a thing with commitment and if I say I'm gonna do something I'm gonna do it. I would never quit a production." When Jessica was asked if she had ever thought of quitting, she replied: "I'm too stubborn to quit. I wouldn't do it. Just because I'm too stubborn. Like 'no, I'll finish it through."' A similar "don't quit" ethic was expressed by Peter, who was both a crew member and had a substantial part in the play:

I very easily could have just whined and complained about it all the time and said I'm not gonna do this, 'cause there were several people who didn't get the part they wanted, like they didn't get a big enough part and so they quit the show or whatever. And that seems ridiculous to me, I mean you just gotta, you know, you have it for a reason, so do it.

It is apparent from these examples that the youth's sense of responsibility did not entirely emerge de novo from their experiences in the programs. Many of these youth appeared to have entered the programs with an inclination to follow through with obligations they had committed themselves to. Nonetheless, similar to the recursive process described by Aristotle earlier, the youth's accounts suggested that the expe- rience of fulfilling new, and perhaps more demanding, expectations deepened their perception of themselves as responsible.

Anticipation of the consequences for others. A related reason youth reported for adhering to demands was their anticipation of how their actions would impact others in the program. This included anticipation of positive impacts from fulfilling the demands, as well as negative effects from not fulfilling them.

These others were sometimes the adult program leaders. Often youth reported feeling respect and warmth toward the leaders and said these feelings led them to make greater effort to accomplish the tasks the leaders handed them. As Sarah from the FFA said:

Mr. Baker and Mr. Jensen are great. They tell you something they think you can achieve and then it's up to you to do that. And I guess it's not like a pressure, but you do, they're such nice people you just kind of wanna live up to their expectations. You never wanna let them down.

Sarah recognized that the demand had come partly from the adults, but she framed her reason for adhering to it in terms of her own agency, her desire to live up to their expectations. LaShawna at Harambee also attributed her increase in responsibility, in part, to a desire to validate the leader's trust in her to complete her assigned tasks, which involved interacting with members outside of the program: "I had to know what I was doing there. And he had to trust me doing that. So I had to be responsible doing that.... A lot of times when you go places I'm not just representing myself, but I'm representing Harambee as well."

Some youth reported adhering to the demands out of consideration, not just for the leaders, but also their peers. Suzanne at Les Miserables explained, "I considered quitting during the program but then I realized that it was way too late and I would be letting down a lot of people. So I think it would have been awful if I would have quit." Charnise, a student from SisterHood, found it difficult to get herself to sell her quota of chocolates to raise money for their year-end retreat but eventually completed the task. When she thought about how she would have approached the task before joining the program, she recalled that her attitude would have been "if I don't get it done, then I don't get it done. No big deal." However, after becoming more connected with the youth in the program, her attitude changed: "Something was like, just do it. Maybe you'll feel better about yourself or something.... Maybe because I have a commitment to them." Although the task was onerous for her, she 
understood that failure to do so would adversely affect others in her program.

Anticipation of consequences for oneself. Another theme that came up in the interviews was the understanding that the completion of certain tasks was important to them personally because of their commitment to superordinate goals. For instance, in Les Miserables, Jessica received a smaller part in the play than she desired; however, the small part still required a large time commitment on her part. When explaining why she stuck with the play despite the small part, Jessica explained, "Some people don't think about this, but the consequences of quitting are immense... if you quit you're almost guaranteed never to get a big part again, and some people don't realize that. But I mean I know that's what can happen." She thus endured the small part in the realization that doing so would help her obtain a larger role in the next production.

Some youth reported accepting and performing tasks because of long-term goals that extended beyond their involvement in the program. For instance, several of the youth in Media Masters and the Clarkson FFA recognized that their work in these programs would help them gain skills and credentials that would aid them in their pursuit of media or agriculture-related careers. This theme was also echoed by Jacob, from The Studio, who noted that many of the tasks he was assigned were ones he did not particularly enjoy. However, he worked hard to accomplish these tasks due, in part, to an understanding that doing so would help position him to progress from his current janitorial job toward a more desirable career in music production.

Finally, one girl, Lori, from the Clarkson FFA, asserted that being asked to do tasks in the programs-even tasks most people would find noxious-was something she considered an honor. She said, "It kinda makes you feel good when they ask you to do things you know like, 'Hey would you like to take a call list?' I mean even something so small like that as calling people for the blood drive." When Lori later elaborated on why she did these tasks, she explained that being asked to do them "makes you feel good because it makes you feel like they know that you're a responsible, dependable person." Lori's account suggests that the development of responsibility may on occasion be motivated by an active desire to see oneself and be seen as by others as responsible.

In sum, the youth reported adhering to program demands because of their commitment and their consideration of consequences. In many cases, they had fulfilled demands because they had accepted the obligation to do so: They had made a willing commitment. But their reasons for sticking with it also included consideration of the consequences of their actions on the leader, their peers, and themselves, including their own character development. They described themselves as exercising personal agency to explain why they persisted and fulfilled the demands that they encountered, but they also recognized the influence of others in shaping their motivation.

\section{Characteristics of Programs With High Rates of Responsibility Development}

The analyses for Questions 1 and 2 suggest that the youth's development of responsibility involved encountering and then adhering to demands. Our final question was, what dynamic features of program environments facilitated this "proximal" developmental process? Youth from Media Masters, Les Miserables, and Clarkson FFA programs were significantly more likely than youth in the other programs to report gaining responsibility. Following the analytic procedures described in the Method section, we evaluated what differentiated these three programs from the others in ways that might be related to facilitating youth's experience of and adherence to demands. We refer to these as programs with "high" and "low" rates of reported responsibility development. The analyses resulted in the identification of three program features that distinguished the high from the low programs.

Youth ownership. First, in the high programs, the leaders consistently cultivated youth's experience of agency over their work. They repeatedly referred to youth's "ownership" and to the work being theirs. In an interview, for example, Janna at Media Masters thought it was essential that youth experience "artistic control" of their work and told the youth, "You have your ideas, follow through. This is your work." Similarly, Mr. Jensen at FFA said, "By allowing them to come up with those ideas, it becomes their ideas." These statements suggest that leaders were reinforcing youth's perception of themselves as willing agents with responsibility for their work and its outcomes.

In contrast, the leader at Faith in Motion never referred to youth ownership, and she controlled program sessions and the dances youth were learning. Emphasis on youth ownership, however, was not entirely unique to the three high programs. The leaders at Prairie County 4-H and Youth Action also used this language frequently and gave the youth considerable control over the selection and execution of program activities. Supporting youth's ownership 
may be a necessary but not sufficient condition for helping youth come to see themselves as more responsible.

A priori structure. Second, while youth ownership was stressed in the three high programs, there was also a high degree of structure. There were rules, deadlines, and ways of doing things, set in advance, that needed to be followed. Media Masters was run like a class with written assignments and schedules. The leader, Janna, said, "I'm here to set a tone and a structure.... It's very important to establish ground rules and guidelines." When students accepted a part in Les Miserables, the youth and their parents were required to sign a contract that laid out specific expectations, including the high demands that would be made on their time. Members of FFA competed in different district and state FFA contests (e.g., on livestock judging, agricultural mechanics, and public speaking), and each was governed by rules and had fixed deadlines. Youth knew what was expected of them when they committed to program activities.

All three high programs also had structured roles for youth, with defined duties and expectations. The FFA chapter had over a dozen officer positions, as well as chair positions for 15 standing committees. All members of Les Miserables had one or more roles in the musical that they had to develop, and all were required to put in $10 \mathrm{hr}$ of tech work. In Media Masters, all youth were required to learn what was involved in the roles of director, cameraperson, and actor and took turns playing each role when they filmed videos. Youth were clearly told what the expectations were for each role.

In contrast, the low programs had less structure and it was more ad hoc. Rules, deadlines, and ways of doing things were developed as work went along. In some programs, this happened because the adults followed a philosophy of youth leadership. They wanted members to organize the activities, which meant that the youth had to create the structure for their work. In some of the other low programs, the adult leaders exercised a high degree of control and imposed the structure as they felt it was needed, rather than in advance. At Faith in Motion, for example, the leader planned each session on a week-to-week basis. Across the low programs, there were also fewer structured roles for youth, and the expectations associated with these roles were less defined. In the low programs, then, the demands on youth were less definite, whereas in the high programs youth's actions occurred within a defined framework; expectations and demands were clear.

High expectations and accountability. Within the three high programs, expectations were not only clear, they were set high and more often linked to consequences. Leaders in the three high programs expected youth to meet deadlines, live up to the demands of their roles, and produce high-quality work. Although these leaders emphasized youth ownership, they also emphasized that youth "have to" or "need to" do certain things. Janna at Media Masters repeatedly reiterated the expectation that "everything is done on time, everything looks good." Youth in Media Masters created multimedia projects and were required on a regular basis to present their work to the leaders and the group to get feedback.

Youth in the high programs also reported holding high expectations for each other. The FFA youth had a collective expectation that members would place highly in regional and state competitions, as they had done in prior years. Members of Les Miserables expressed a shared expectation that everyone would work hard and use time productively. Suzanne, a ninth-grader, reported: "I really get frustrated when someone is not giving $100 \%$ or they are wasting your time, because I've seen the value of like each second." Across the three programs, there was a shared ethos across leaders and youth that high-quality work was expected.

Accountability in the high programs was vested in individual youth. The FFA leaders, for example, reminded youth of the obligations they had taken upon themselves by getting elected to officer positions. As Mr. Jensen said:

We try to impress upon our officers that ultimately everything that we say we want to get done, it's your responsibility to get it done. We don't expect any of you to do all the work. We expect you to help our troops together, to work together to get those things done, but if we can't get anyone else there, ultimately the job falls back on your shoulders.

Adult leaders from the three high programs indicated that they did not "rescue" youth. Mr. Jensen described how some leaders in FFA programs end up doing a lot of the written work that is required by the state FFA office but said, "Mr. Baker and I do not do that. If our kids don't do it, it doesn't get done."

There were tangible consequences associated with youth fulfilling or failing to fulfill demands. When a lead actress at Les Miserables had not put in her required hours with the production's technical crew, the leaders made clear that her choice was to do them immediately or be out of the show. Actors in Les Miserables were also required to keep their grades up in classes, and one student was in fact dropped from the production because his grades fell below the 
required standard. As Ann explained, "Each Thursday or Friday a list [of grades] comes out. If they are not academically where they should be, they can come to practices but they can't participate. I mean it's a very strict code and we live by that." Positive consequences in these programs were also linked to fulfilling expectations. For example, actors in Les Miserables knew that they improved their chances of receiving major roles in future productions by demonstrating that they could be relied on to carry out and excel in minor roles.

In contrast, in the low programs, leaders had lower expectations and more often let youth "off the hook." They filled in or covered up for weaker work. In several cases, when members of Youth Action did not complete or backed out on doing a task, the leader reported doing the work himself. Similarly, when several youth at Art-First fell behind schedule in painting their murals, the situation was not formulated or handled in terms of individual accountability. Instead, other youth and even additional adults were enlisted on the final day to help the slower individuals complete the murals in time. Leaders in some of these programs held youth accountable for attendance and following rules, but not for the completion or quality of their work. Youth at Harambee, for example, were paid for their participation, as they were at Media Masters, and several were docked pay or terminated from the program for being repeatedly late or missing days. But unlike at Media Masters, youth were not held to high standards of accountability for their work.

\section{Conclusion}

These findings suggest features in the three programs that may have facilitated the process described in the analyses for Questions 1 and 2 . Youth in these programs were encouraged to experience ownership of their actions-to see themselves as agents making willing choices to take on demands. At the same time, their actions needed to occur within an a priori structure: The task demands, time demands, and role demands were unambiguous and clearly defined. Furthermore, meeting and completing these demands was perceived as normative within the program-it was expected, it was part of the program culture. And meeting or failing to meet the expectations in these programs had consequences for both the individual and the group.

In sum, the three high programs appeared to support the process of responsibility development by providing substantial demands, supporting youth's ownership of these demands, and providing meaningful individual consequences that helped youth adhere to them. Although exploratory, these findings suggest plausible theoretical linkages between the process of responsibility development, based on the youth's reports, and dynamic features of the program environment, based on discussions with the leaders and observations of the programs.

\section{Discussion}

This research demonstrates that youth programs can be contexts where youth develop a sense of responsibility, and it provides an account of the process that may underlie this developmental change. We found that approximately half of the youth in 3 of 11 programs we studied described becoming more responsible as a salient outcome of their participation. Given the importance of responsibility to adult work and family roles (Arnett, 2000; Barrick \& Mount, 1991), and given that youth may have limited opportunities to develop responsibility in other contexts of their lives (Schlegel \& Barry, 1991), these findings suggest an important role that the larger context of youth programs can play in the development of their participants.

The strength of our qualitative approach is that it provides an account of the proximal processes underlying the development of responsibility, as they are experienced by youth. A useful and perhaps undervalued place for understanding the nature of environmental effects on youth development is to ask youth to detail their own experience of the change process (Spencer, 2006). It should be kept in mind, however, that the process described here is based on preliminary findings, principally from youth's narrative reports, and are in need of more rigorous testing and confirmation. In this discussion, we examine what the analysis suggests about this change process, how programs might facilitate it, and then discuss implications for future research.

\section{The Process of Becoming Responsible}

The most important component to the process of developing responsibility appeared to be the youth's execution of demands. The demands that youth performed took different forms and came in different ways. The three types of demands that we identified-task demands, role demands, and time demands-all included expectations that were structured into the program. These demands were often perceived as difficult or as entailing more than the 
youth had originally bargained for. For example, Sarah found herself having to put in extra effort to maintain the health of the pigs in her FFA project, and the Les Miserables actors found they had to forego sleep and restrict their social lives to fulfill the demands of rehearsals. These findings suggest that although program leaders often feel the pressure to make activities fun, youth may be most likely to experience gains in responsibility precisely from the activities they complete that are challenging, onerous, or require self-discipline.

In the youth's accounts, the key to gaining responsibility was in their sticking with and fulfilling these demands. For many youth we interviewed, their reasons for persevering included a feeling of obligation to complete demands that they had taken upon themselves. Youth also pointed to the anticipation of future consequences to others and themselves as the reasons why they persevered in the demanding situations. This latter reason is reminiscent of the findings that young children are better able to exercise self-control in the face of tempting alternatives if they have a future orientation and can anticipate rewards for obedient behavior (Metcalfe \& Mischel, 1999). Adolescents are at a developmental stage where they are acquiring new cognitive tools that make them more able to anticipate long-term and abstract future consequences of their actions (Keating, 2004) that may help them persevere through difficult and onerous tasks.

The youth's explanations for why they adhered to expectations suggested the importance of both social controls and personal agency in the development of responsibility. Both appeared to be important for understanding adherence to program demands. Consistent with social control explanations (Sampson \& Laub, 1992), some youth described feeling compelled by the negative consequences that nonadherence would have on their future opportunities and on their standing with leaders and peers in the program. These youth described their actions as being almost compulsory (e.g., "I needed to" and "I had to"). Yet, consistent with the proposed importance of social investments (Roberts et al., 2005), youth generally described themselves as active agents in the execution of demands, and cast their reasons for adhering to the demands as emanating from themselves (e.g., "I wanted to help the group" and "I decided to"). Even when youth said they "had to" perform certain tasks, this urgency often originated from their understanding that the tasks were important for the attainment of personal goals (e.g., "I have to do this in order to obtain better roles in the future"). In this sense, youth appeared to be agents of their own development (Larson, 2000). Their active and willful commitment to the demands was important to the developmental process (Roberts et al., 2005). Thus, although it is essential to recognize that this developmental process took place within the context of external demands, expectations, and consequences, it should not be expected that leaders can simply impose demands on youth and expect positive outcomes when the demands are not linked to goals that are important for the youth.

\section{The Role of Programs in Facilitating the Development of Responsibility}

The three programs in which responsibility development was most common provided contexts that appeared particularly suited to facilitating the process described by the youth. Leaders encouraged youth to take ownership over demanding tasks and roles, thus providing conditions for youth to demonstrate that they could be depended on in meaningful situations. These tasks occurred within an unambiguous structured framework; therefore, youth knew what they had to do to be successful. Furthermore, expectations from both the leaders and peers were high and there were important consequences associated with these demands, so youth experienced compelling reasons to fulfill the demands. The leaders used the language of "responsibilities" and "duties," and youth in these programs appeared to internalize a sense of obligation to complete activities, even when they became onerous. In sum, these three program contexts appeared to be organized to provide optimal conditions for youth to experience the proximal developmental processes that caused youth to experience themselves as more responsible.

It is also important to note that although the development of responsibility was not as salient for youth in the other eight programs, these youth frequently reported developing in other significant ways due to program experiences. For instance, in separate analyses, we found that participation in Youth Action-a program with almost no members mentioning increases in responsibility-frequently facilitated the development of strategic thinking (Larson \& Hansen, 2005), multicultural competencies (Watkins, Larson, \& Sullivan, 2007), and increased general motivation (Pearce \& Larson, 2006). Similarly, the youth at ArtFirst gained artistic skills, resilience (Larson \& Walker, 2006), and social capital (Jarrett, Sullivan, \& Watkins, 2005). Even though responsibility development was not salient to youth in these programs, evidence suggests that these programs provided environmental conditions that facilitated development in other domains.

Our understanding of why these programs had features less conducive to the development of 
responsibility should be viewed with sensitivity to the different challenges faced by these programs. All three of the high programs were in schools and, as a result, had a more readily available pool of participants. These leaders thus did not face the same pressure to recruit and retain youth encountered by many community-based programs (NRC, 2002) and may have had an easier time imposing demands on youth without fear of alienating and losing them. It will be important to define further the program features that facilitate the development of responsibility and to understand ways in which these features coalesce or compete with other program goals such as retaining participants or facilitating the development of other characteristics.

\section{Future Research}

The current research begins to develop an ecologically grounded theory of the process underlying the development of responsibility. Future research is needed to refine, revise, and test this preliminary account. Given the limits and potential biases in narrative reports, a natural next step is to evaluate and expand on these qualitative findings through quantitative research (Brunswik, 1952; Gibbs, 1979). Quantitative studies using behavioral measures of responsibility, repeated assessments, and larger numbers of youth and programs will permit more definitive tests of the process suggested by the current qualitative investigation. Obtaining assessments of responsible behavior from other contexts of youth's lives (e.g., at home, in class, or in future jobs) would also clarify the extent to which changes in the program transfer to behavior in other settings (Wood, 2007).

An objective of subsequent research should be to evaluate the process suggested here with representative samples of both programs and youth. This study intentionally focused on a sample of "high-quality programs" in order to increase the likelihood of observing youth who experienced positive developmental effects through program participation. Research across a wider range of programs is needed. Furthermore, the analyses here focused on a subsample of youth for whom responsibility development was particularly salient. This intentional method is appropriate for discovery research, where the aim is to understand a process such as the development of responsibility (Strauss \& Corbin, 1998). Nonetheless, more representative sampling would help to evaluate the generality of the process described here across diverse youth, including those differing in their initial levels of responsibility.
Finally, although the current findings shed light on the process underlying the development of responsibility in youth programs, they also point to investigations that could further elaborate this process. Apart from simply encountering demands, we found how youth construe the program and the people in the program may be critical. Further research will need to examine how a youth's adherence to demands depends on the quality of their relationship with leaders or other youth in the program. Our analysis also suggests that programs facilitate the development of responsibility by giving youth ownership at the same time that they are held accountable for the demands they take on. Further discovery research would help to illuminate how successful programs balance the seemingly incongruent task of providing support to youth while, at the same time, enforcing individual accountability. As discussed at the outset, responsibility is an important characteristic for many aspects of adult life, and many youth programs see the development of responsibility as an explicit part of their mission. Research that improves our understanding of this process will provide guidelines to achieving this important goal.

\section{References}

Aristotle. (1962). Nicomachean ethics (M. Ostwald, Trans.). Indianapolis, IN: Bobbs-Merrill.

Arnett, J. (2000). Emerging adulthood: A theory of development from the late teens through the twenties. American Psychologist, 55, 469-480.

Auerbach, C. F., \& Silverstein, L. B. (2003). Qualitative data: An introduction to coding and analysis. New York: New York University Press.

Barrick, M. R., \& Mount, M. K. (1991). The Big Five personality dimensions and job performance: A metaanalysis. Personnel Psychology, 44, 1-26.

Bogg, T., \& Roberts, B. W. (2004). Conscientiousness and health behaviors: A meta-analysis. Psychological Bulletin, 130, 887-919.

Boy Scouts of America. (2007). Boy Scouts of America: Mission statement. Retrieved May 18, 2007, from http:// www.scouting.org/legal/mission.html

Bronfenbrenner, U. (1999). Environments in developmental perspective: Theoretical and operational models. In S. L. Friedman \& T. D. Wachs (Eds.), Measuring environment across the life span: Emerging methods and concepts (pp. 3-28). Washington, DC: American Psychological Association.

Brunswik, E. (1952). The conceptual framework of psychology. Chicago: University of Chicago Press.

Creswell, J. W. (1998). Qualitative inquiry and research design: Choosing among five traditions. Thousand Oaks, CA: Sage.

Eccles, J., Barber, B., Stone, M., \& Hunt, J. (2003). Extracurricular activities in adolescent development. Journal of Social Issues, 59, 865-889. 
Gibbs, J. C. (1979). The meaning of ecologically oriented inquiry in contemporary psychology. American Psychologist, 34, 127-140.

Girl Scouts of the USA. (2007). Girl Scouts of the USA: Program goals. Retrieved May 18, 2007, from http:// www.girlscouts.org/program/

Habermas, T., \& Bluck, S. (2000). Getting a life: The emergence of the life story in adolescence. Psychological Bulletin, 126, 748-769.

Hogan, R., \& Roberts, B. W. (2004). A socioanalytic model of maturity. Journal of Career Assessment, 12, 207-217.

Jarrett, R., Sullivan, P., \& Watkins, N. (2005). Developing social capital through participation in organized youth programs: Qualitative insights from three programs. Journal of Community Psychology, 33, 41-55.

Jorgensen, D. L. (1989). Participant observation: A methodology for human services. Thousand Oaks, CA: Sage.

Judge, T. A., Heller, D., \& Mount, M. K. (2002). Five-factor model of personality and job satisfaction: A metaanalysis. Journal of Applied Psychology, 87, 530-541.

Keating, D. (2004). Cognitive and brain development. In R. M. Lerner \& L. Steinberg (Eds.), Handbook of adolescent psychology (pp. 45-84). New York: Wiley.

Kochanska, G. (1997). Multiple pathways to conscience for children with different temperaments: From toddlerhood to age 5. Developmental Psychology, 33, 228-240.

Kochanska, G., Murray, K. T., \& Harlan, E. T. (2000). Effortful control in early childhood: Continuity and change, antecedents, and implications for social development. Developmental Psychology, 36, 220-232.

Larson, R. (2000). Toward a psychology of positive youth development. American Psychologist, 55, 170-183.

Larson, R., \& Hansen, D. (2005). The development of strategic thinking: Learning to impact human systems in a youth activism program. Human Development, 48, 317-349.

Larson, R., Jarrett, R., Hansen, D., Pearce, N., Sullivan, P., Walker, K. et al. (2004). Organized youth activities as contexts for positive development. In P. A. Linley \& S. Joseph (Eds.), Positive psychology in practice (pp. 540-560). New York: Wiley.

Larson, R., Pearce, N., Sullivan, P., \& Jarrett, R. L. (2007). Participation in youth programs as a catalyst for negotiation of family autonomy with connection. Journal of Youth and Adolescence, 36, 31-45.

Larson, R. W., \& Walker, K. C. (2006). Learning about the "real world" in an urban arts youth program. Journal of Adolescent Research, 21, 244-268.

Lincoln, Y. S., \& Guba, E. G. (1985). Naturalistic inquiry. Newbury Park, CA: Sage.

Mahoney, J. L., Larson, R., Eccles, J., \& Lord, H. (2005). Organized activities as developmental contexts for children and adolescents. In J. Mahoney, R. Larson, \& J. Eccles (Eds.), Organized activities as contexts of development (pp. 3-22). Mahwah, NJ: Erlbaum.

McLaughlin, M. (2000). Community counts: How youth organizations matter for youth development. Washington, DC: Public Education Network.
McLaughlin, M. W., Irby, M. A., \& Langman, J. (1994). Urban sanctuaries: Neighborhood organizations in the lives and futures of inner-city youth. San Francisco: JosseyBass.

Metcalfe, J., \& Mischel, W. (1999). A hot/cool-system analysis of delay of gratification: Dynamics of willpower Psychological Review, 106, 3-19.

Miles, M., \& Huberman, A. M. (1994). Qualitative data analysis (2nd ed.). Thousand Oaks, CA: Sage.

Moustakas, C. (1994). Phenomenological research methods. Thousand Oaks, CA: Sage.

National FFA Organization. (2007). The FFA mission. Retrieved May 18, 2007, from http://www.ffa.org/index. cfm?method=c_about.mission

National Institutes of Mental Health Consortium of Editors on Development and Psychopathology. (1999). Editorial statement. Journal of Research on Adolescence, 9, $489-490$.

National Research Council Institute of Medicine. (2002). Community programs to promote youth development. Washington, DC: National Academy Press.

Noftle, E. E., \& Robins, R. W. (2007). Personality predictors of academic outcomes: Big Five correlates of GPA and SAT scores. Journal of Personality and Social Psychology, 93, 116-130.

Partnership for 21st Century Skills. (2003). Learning for the 21st century. Retrieved November 8, 2004, from http:/ / www.21stcenturyskills.org

Pearce, N., \& Larson, R. (2006). The process of motivational change in a civic activism organization. Applied Developmental Science, 10, 121-131.

Roberts, B. W. (1997). Plaster or plasticity: Are adult work experiences associated with personality change in women? Journal of Personality, 65, 205-232.

Roberts, B. W., \& Bogg, T. (2004). A 30-year longitudinal study of the relationships between conscientiousnessrelated traits, and the family structure and healthbehavior factors that affect health. Journal of Personality, 72, 325-354.

Roberts, B. W., Bogg, T., Walton, K. E., Chernyshenko, O. S., \& Stark, S. E. (2004). A lexical investigation of the lower-order structure of conscientiousness. Journal of Research in Personality, 38, 164-178.

Roberts, B. W., \& Wood, D. (2006). Personality development in the context of the neo-socioanalytic model of personality. In D. Mroczek \& T. Little (Eds.), Handbook of personality development (pp. 11-39). Mahwah, NJ: Erlbaum.

Roberts, B. W., Wood, D., \& Smith, J. L. (2005). Evaluating Five Factor Theory and social investment perspectives on personality trait development. Journal of Research in Personality, 39, 166-184.

Robins, R. W., Noftle, E. E., Trzesniewski, K. H., \& Roberts, B. W. (2005). Do people know how their personality has changed? Correlates of perceived and actual personality change in young adulthood. Journal of Personality, 73, $489-521$. 
Roth, J., \& Brooks-Gunn, J. (2003). Youth development programs: Risk, prevention and policy. Journal of Adolescent Health, 32, 170-182.

Sampson, R. J., \& Laub, J. H. (1992). Crime and deviance in the life course. Annual Review of Sociology, 18, 63-84.

Saulsman, L. M., \& Page, A. C. (2004). The five-factor model and personality disorder empirical literature: A meta-analytic review. Clinical Psychology Review, 23, $1055-1085$.

Schlegel, A., \& Barry, H. (1991). Adolescence: An anthropological inquiry. New York: Free Press.

Secretary's Commission on Achieving Necessary Skills. (1991). What work requires of schools: A SCANS report for America 2000. Washington, DC: U.S. Department of Labor.

Spencer, M. B. (2006). Phenomenology and ecological systems theory: Development of diverse groups. In R. M. Lerner \& W. Damon (Eds.), Handbook of child psychology: Vol. 1. Theoretical models of human development (6th ed., pp. 829-893). New York: Wiley.

Strauss, A., \& Corbin, J. (1998). Basics of qualitative research: Techniques and procedures for developing grounded theory (2nd ed.). Thousand Oaks, CA: Sage.

Taylor, S. J., \& Bogdan, R. (1998). Introduction to qualitative research methods: $A$ guidebook and resource (3rd ed.). New York: Wiley.
Warton, P. M. (2001). The forgotten voices in homework: Views of students. Educational Psychologist, 36, 155-165.

Watkins, N., Larson, R., \& Sullivan, P. (2007). Learning to bridge difference: Community youth programs as contexts for developing multicultural competencies. American Behavioral Scientist, 51, 380-402.

Wilson, T. D. (2002). Strangers to ourselves: Discovering the adaptive unconscious. Cambridge, MA: Harvard University Press.

Winter, D. G. (1992). Responsibility. In C. P. Smith \& J. W. Atkinson (Eds.), Motivation and personality: Handbook of thematic content analysis (pp. 500-505). New York: Cambridge University Press.

Wood, D. (2007). Using the PRISM to compare the explanatory value of general and role-contextualized trait ratings. Journal of Personality, 75, 1103-1126.

Wood, D., Gosling, S. D., \& Potter, J. (2007). Normality evaluations and their relation to personality traits and well-being. Journal of Personality and Social Psychology, 93, $861-879$.

Wood, D., \& Roberts, B. W. (2006). The effect of age and role information on expectations for Big Five personality traits. Personality and Social Psychology Bulletin, 32, 1482 1496.

Yalom, I. D. (1980). Existential psychotherapy. Itasca, IL: F.E. Peacock. 